\title{
Subseasonal Variability of the Southeast Pacific Stratus Cloud Deck*
}

\author{
HAIMING XU \\ International Pacific Research Center, School of Ocean and Earth Science and Technology, University of Hawaii at Manoa, \\ Honolulu, Hawaii \\ Shang-Ping Xie And YuQing Wang \\ International Pacific Research Center, and Department of Meteorology, School of Ocean and Earth Science and Technology,
} University of Hawaii at Manoa, Honolulu, Hawaii

(Manuscript received 15 January 2004, in final form 10 June 2004)

\begin{abstract}
Subseasonal variability of the stratus/stratocumulus cloud deck over the subtropical southeast Pacific is studied using satellite and buoy observations as well as the NCEP-NCAR reanalysis. It is found that subseasonal variability in the stratus cloud deck is closely related to variations in surface wind velocity, water vapor, sea level pressure, and 500-hPa geopotential height. An increase in cloud liquid water (CLW) over the subtropical southeast Pacific is found to be associated with the development of an anomalous anticyclonic circulation to the south off the west coast of Chile. The enhanced southerly to southeasterly winds advect cold and dry air into the stratus region against the mean sea surface temperature (SST) gradient. This cold and dry advection, together with increased wind speed, intensifies surface latent and sensible heat fluxes and destabilizes the boundary layer. Anomalous offshore easterlies north of the anomalous anticyclone cause a low-level divergence. The associated subsidence warming, together with the cold advection in the surface layer, strengthens the temperature inversion, conducive to the development of stratus clouds. Buoy observations confirm this subseasonal cloud variability and its relationship with surface meteorological variables.

A lead/lag composite analysis indicates that circulation variables such as sea level pressure and surface wind lead cloud liquid water by 1-2 days while SST lags CLW by 1-2 days, suggesting that low-cloud variability is caused by atmospheric circulation changes rather than by the underlying ocean. The dynamic adjustment that leads to cloud fluctuations and possible orographic effects of the Andes are also discussed.
\end{abstract}

\section{Introduction}

Stratocumulus (Sc) clouds often develop over the subtropical eastern oceans and play an important role in the regional and global climate by reflecting solar radiation back to space and thereby reducing the downward solar radiation at the surface. Because of their low altitude, their effect on longwave radiation is rather small. As a result, Sc clouds have a net cooling effect on both the ocean surface and the atmosphere and may affect basin-scale and global climates. For example, general circulation model (GCM) studies show that the

\footnotetext{
* International Pacific Research Center Contribution Number 283 and School of Ocean and Earth Science and Technology Contribution Number 6431.

Corresponding author address: Dr. Haiming Xu, International Pacific Research Center, School of Ocean and Earth Science and Technology, University of Hawaii at Manoa, 2525 Correa Road, Honolulu, HI 96822.

E-mail: hxu@hawaii.edu
}

Sc cloud deck over the subtropical southeast Pacific reduces the incoming solar radiation at the sea surface and cools the local sea surface temperature (SST), triggering a coupled ocean-atmospheric adjustment that strengthens the climatic asymmetry in both east-west and north-south directions across the basin [see Xie (2004a) for a recent review of studies of eastern Pacific climate and the role of air-sea interaction].

Global studies of temporal variability of low clouds using surface-based observations have focused on seasonal mean properties and show that seasonal to interannual variations in low-cloud amount are closely related to variations in atmospheric circulation, SST, and stability of the lower troposphere (Klein and Hartmann 1993; Weare 1994; Norris and Leovy 1994; Klein et al. 1995). These studies indicate that low-cloud amount anomalies are often negatively correlated with SST anomalies because of a positive feedback: a decrease in SST increases the stability of the lower troposphere and thus low-cloud amount, while the increased cloud amount in turn cools the ocean further. While this SSTcloud correlation tends to be negative on the basin scale 
that the sparse ship observations can resolve, new highresolution satellite observations show that this correlation may become positive on smaller spatial scales (a few hundred kilometers; Xie 2004b). On these scales, the moisture convergence effect dominates, with increased low-cloud amount over positive SST anomalies.

Studies of Sc cloud variability at diurnal and synoptic time scale have been restricted to the Northern Hemisphere (NH) during boreal summer, the season when these clouds are well developed (Klein 1997). Wylie et al. (1989) studied synoptic variations in low-cloud amount during the First ISCCP (International Satellite Cloud Climatological Project) Regional Experiment (FIRE; Albrecht et al. 1988). They found that increases in low-cloud amount were statistically related to increases in cold advection in the planetary boundary layer (PBL), increases in 500-hPa height, and decreases in boundary layer depth. Klein (1997) analyzed synoptic variations in low-cloud properties using the long observational record from Ocean Weather Station November $\left(30^{\circ} \mathrm{N}, 140^{\circ} \mathrm{W}\right)$ and found that low-cloud amount was strongly correlated with temperature advection, the stability of the lower troposphere, and the relative humidity of the cloud layer. At diurnal time scales, the daily maximum in Sc clouds generally occurs just before dawn and the minimum near 1500 local time over oceans (Minnis et al. 1992; Rozendaal et al. 1995; Bretherton et al. 1995; Wood et al. 2002; among others). The shortwave absorption by clouds in the afternoon leads to a "decoupling" of turbulent circulations in the cloud layer from those in the subcloud layer, resulting in a thinning of the cloud layer depth (Nicholls 1984; Betts 1990). Decoupling is considered to be an important process in the diurnal cycle of low clouds.

Recently, Rozendaal and Rossow (2003) examined some aspects of intraseasonal variability of boundary layer cloud deck over the northeast Pacific and its association with the general circulation during the $\mathrm{NH}$ winter using combined data from the ISCCP and the European Centre for Medium-Range Weather Forecasts (ECMWF) reanalysis. They speculated that changes in cloud properties could be the result of changes in the large-scale circulation.

In comparison to the NH Sc cloud decks, subseasonal variability in marine stratocumulus clouds over the southeast Pacific has not been studied adequately despite their importance for tropical eastern Pacific climate (Philander et al. 1996; Gordon et al. 2000; Xie 2004a). Spare ship observations over the South Pacific do not adequately resolve subseasonal variability. Here we use a suite of satellite observations to study subseasonal variability in Sc clouds over the subtropical southeast Pacific and its relationship with atmospheric circulation and SST. We will show that there is considerable variability in 2-week and intraseasonal (40-80 days) bands in association with cold advection in the PBL. There is some indication that the cold advection results from the interaction of midlatitude atmospheric distur- bances with the Andes. Since Sc cloud is a result of complex interaction of dynamics, thermodynamics, and microphysics, a description of its subseasonal cloud variability and the relation with dynamic and thermodynamic fields serves as a benchmark for model simulations in this climatically important region. Such a critical comparision of simulation and observations may help improve atmospheric general circulation models which tend to underestimate the amount of low clouds over subtropical eastern oceans (e.g., Del Genio et al. 1996; Ma et al. 1996).

The rest of the paper is organized as follows. The next section describes the datasets and statistical methods used in this study. Section 3 examines subseasonal variability in marine $\mathrm{Sc}$ clouds over the southeast $\mathrm{Pa}$ cific and its relationship with atmospheric circulation. Section 4 discusses the circulation changes that lead to cloud fluctuations. Section 5 is a summary.

\section{Data and statistical methods}

\section{a. Satellite data}

The paucity of ship observations limits their use to studying variability that is monthly or longer in time and $1000 \mathrm{~km}$ or larger in space. New satellite observations offer a view of the vast oceans and overlying atmosphere in detail never possible before (Wentz et al. 2000; Hashizume et al. 2002; Xie et al. 2001; see Xie $2004 \mathrm{~b}$ for a review). This study uses observations made by the Special Sensor Microwave Imager (SSM/I), Tropical Rainfall Measuring Mission (TRMM) microwave imager (TMI), and microwave scatterometer on the QuikSCAT satellite.

SSM/I measures column-integrated cloud liquid water (CLW), column water vapor, sea surface wind speed, and rain rate over the global ocean at a $0.25^{\circ}$ resolution (Wentz 1997). Here we use a daily product derived from a 3-day running mean of F15 SSM/I measurements on the Defense Meteorological Satellite Program (DMSP) satellite for three years from January 2000 to December 2002. The SSM/I satellite flies on a near-polar, sun-synchronous orbit and crosses the equator at the same local times each day, at 2131 local time on the ascending and 0931 on the descending track.

TMI also measures CLW over the global Tropics within $40^{\circ} \mathrm{N} / \mathrm{S}$, but unlike SSM/I, the TRMM satellite travels from west to east in a semiequatorial orbit and takes about 45 days for an exact repeat of its orbit. Thus data are collected at changing local times at any given location on the earth. As a result, subseasonal variability is aliased by the strong diurnal cycle of stratus clouds in the subtropical South Pacific (Wood et al. 2002; Bretherton et al. 2004). For this reason, we do not use TMI CLW in this study. TMI carries a $10.7-\mathrm{GHz}$ channel, which allows the measurement of SST nearly free of clouds (Wentz et al. 2000). Since the SST diurnal cycle is weak $\left(\sim 0.25^{\circ} \mathrm{C}\right.$ in amplitude), TMI SSTs are 
not severely aliased at subseasonal time scale by the diurnal cycle. We use a TMI SST dataset on a $0.25^{\circ}$ grid.

The microwave scatterometer on the QuikSCAT satellite measures surface wind velocity over the World Ocean. Like the SSM/I satellite, the QuikSCAT satellite also flies on a near-polar, sun-synchronous orbit and crosses the equator twice, at 0551 local time on the ascending and 1751 on the descending track. To be consistent with the SSM/I product, we use a daily mean dataset of QuikSCAT wind velocity on a $0.25^{\circ}$ grid for the same period of 2000-02. SSM/I, TMI, and QuikSCAT data are all downloaded from the Web site of Remote Sensing Systems (http://www.ssmi.com).

\section{b. Buoy observations and reanalysis}

An improved meteorology (IMET; Hosom et al. $1995)$ buoy is deployed at $20.15^{\circ} \mathrm{S}, 85.15^{\circ} \mathrm{W}$ by the Woods Hole Oceanographic Institution (WHOI) as part of the Eastern Pacific Climate Investigation (EPIC) program (Bretherton et al. 2004). The IMET system makes observations of wind velocity, relative humidity, surface air and ocean temperatures, incoming shortwave radiation, and precipitation. The buoy data are used to compute hourly averaged surface heat fluxes using a bulk algorithm (Weller and Anderson 1996). We use daily averaged data based on the hourly data for a 2-yr period from 7 October 2000 to 22 October 2002 (available online at http://uop.whoi.edu/ stratus/archival_data.html).

In addition, we use the daily averaged National Centers for Environmental Prediction-National Center for Atmospheric Research (NCEP-NCAR) reanalysis data (Kalnay et al. 1996) on a $2.5^{\circ} \times 2.5^{\circ}$ grid, for sea level pressure (SLP) and 500-hPa geopotential height.

\section{c. Statistical methods}

To determine statistical significance, we use the method of Klein (1997) to estimate autocorrelation decay time. For each variable the 1-day lag autocorrelation coefficient, $r$, is first calculated, and the time in days between independent observations, $\tau$, is defined as $-2(\ln r)^{-1}$, following Leith (1973). (If $\tau$ is less than one day, then it is set to one day). In assessing the significance of correlations between two variables (say $x$ and $y$ ), the number of independent paired observations is required. This number is assigned to be the length of observations divided by the maximum of $\tau_{x}$ and $\tau_{y}$. Significance is then determined using a standard $t$ test with the cross-correlation coefficient, the number of independent paired observations, and a specified confidence level.

\section{Subseasonal variability}

Figure 1a shows the distribution of the 3-yr (2000-02) mean SSM/I precipitation and CLW in the eastern $\mathrm{Pa}$ cific. Large precipitation is observed in the South $\mathrm{Pa}$ cific convergence zone (SPCZ) and the ITCZ north of
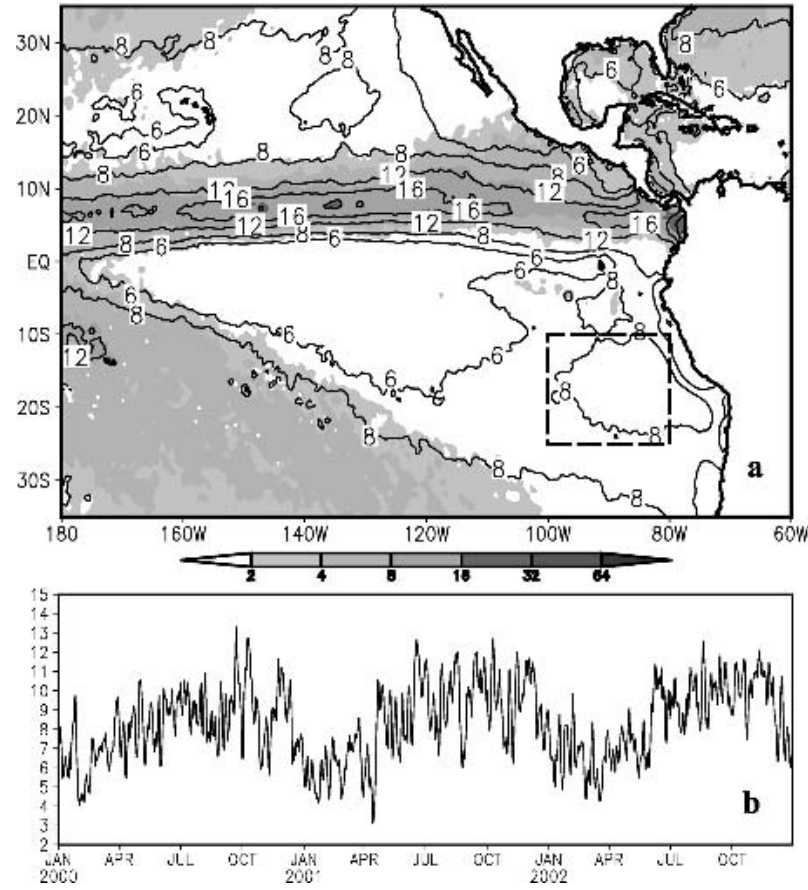

FIG. 1. (a) Three-year (2000-02) mean SSM/I column cloud liquid water (contour in $10^{-2} \mathrm{~mm}$ ) and precipitation (shaded in $\left.\mathrm{mm} \mathrm{day}^{-1}\right)$ and (b) time series of column cloud liquid water $\left(10^{-2}\right.$ $\mathrm{mm})$ averaged over the southeast Pacific stratus cloud deck $\left[10^{\circ}-\right.$ $25^{\circ} \mathrm{S}, 80^{\circ}-100^{\circ} \mathrm{W}$; dashed box in (a)].

the equator where CLW is closely related to deep clouds. In the subtropical North Pacific and a wedgelike region over the southeast Pacific, on the other hand, nonprecipitating clouds dominate, with CLW reaching a maximum of above $0.08 \mathrm{~mm}$ on each side of the equator, off the west coasts of Mexico and South America. Typically, stratus/Sc clouds dominate these two subtropical regions. This study focuses on the southeast Pacific Sc cloud deck.

The CLW time series over the southeast Pacific displays a pronounced annual cycle, with its maximum in local spring and minimum in local summer (Fig. 1b). We use the annual and semiannual harmonics to represent the seasonal cycle and define subseasonal anomalies as deviations from this seasonal cycle plus the 3 -yr mean. Figure 2 shows the temporal evolution of the CLW anomaly averaged in $10-25^{\circ} \mathrm{S}, 80-100^{\circ} \mathrm{W}$ (the dashed box in Fig. 1a, a region encompassing the maximum CLW in the mean). There is considerable subseasonal variability in this area-averaged time series, with a standard deviation of $1.5 \times 10^{-2} \mathrm{~mm}$ or $15 \%$ of the mean. We apply a Morlet wavelet to the CLW time series to obtain a local wavelet power spectrum (Fig. 3). Significant power concentrates mainly on two bands, one at about 8-16 days and one at 40-80 days. Interestingly, the CLW spectrum has a significant 40-50 day peak in the late fall and early winter of 2001 and a 60-70 day peak in the late spring of 2000 and 2001. 
2000
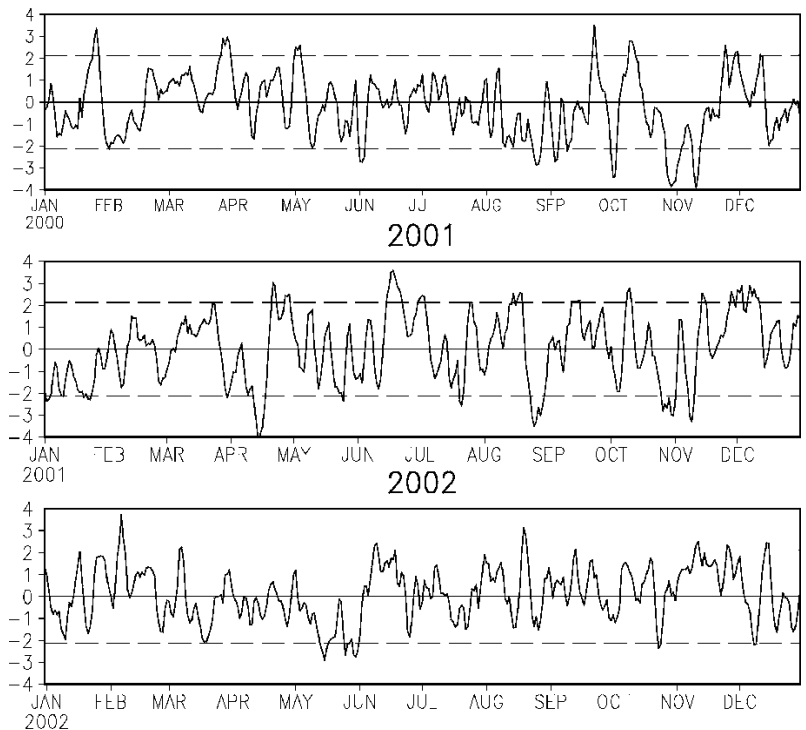

FIG. 2. Time series of column cloud liquid water $\left(10^{-2} \mathrm{~mm}\right)$ averaged over the southeast Pacific deck $10^{\circ}-25^{\circ} \mathrm{S}, 80^{\circ}-100^{\circ} \mathrm{W}$ in $2000-02$. Seasonal variations are removed with a harmonic analysis. Dashed lines indicate 1.5 times the standard deviation.

\section{a. Analysis of buoy observations}

This subsection examines the effect of cloud fluctuations on incoming solar radiation and its relationship with surface meteorological variables as observed by the IMET buoy under the Sc cloud deck. A major role of low clouds in climate is to reflect solar radiation and reduce its value at the sea surface (Randall et al. 1984). Figure 4 presents the time series of incoming shortwave radiation anomaly at the IMET buoy and SSM/I column CLW anomaly at $\left(20.125^{\circ} \mathrm{S}, 85.125^{\circ} \mathrm{W}\right)$, which is the nearest grid point to the buoy $\left(20.15^{\circ} \mathrm{S}, 85.15^{\circ} \mathrm{W}\right)$. The SSM/I CLW and buoy-measured incoming radiation are negatively correlated, with their correlation coefficient as high as 0.53 for $1 \mathrm{yr}$ and 0.49 for the 2-yr period when the IMET observations are available, both significant at the $99.9 \%$ level based on the statistical methods as described in section 2c.

The high correlation with the buoy-measured incoming solar radiation indicates that SSM/I CLW may be used to study the cloud-radiation effect in this region. The typical range of the subseasonal variability is 0.05 $\mathrm{mm}$ (or $50 \%$ of the mean) for CLW and $40 \mathrm{~W} \mathrm{~m}^{-2}$ (or $20 \%$ of the mean) for surface solar radiation (Fig. 4), indicating that Sc clouds play a significant role in radiation balance at the sea surface.

Table 1 lists the correlation coefficients between $\mathrm{SSM} / \mathrm{I} \mathrm{CLW}$ at $20.125^{\circ} \mathrm{S}, 85.125^{\circ} \mathrm{W}$ and some other variables measured by the buoy. The most significant correlation is with the incoming shortwave radiation, as discussed earlier. In addition, SSM/I CLW is positively correlated with surface wind speed, consistent with Klein's (1997) analysis of observations at an ocean weather station over the northeast Pacific. He suggested that the wind speed correlation is indicative of

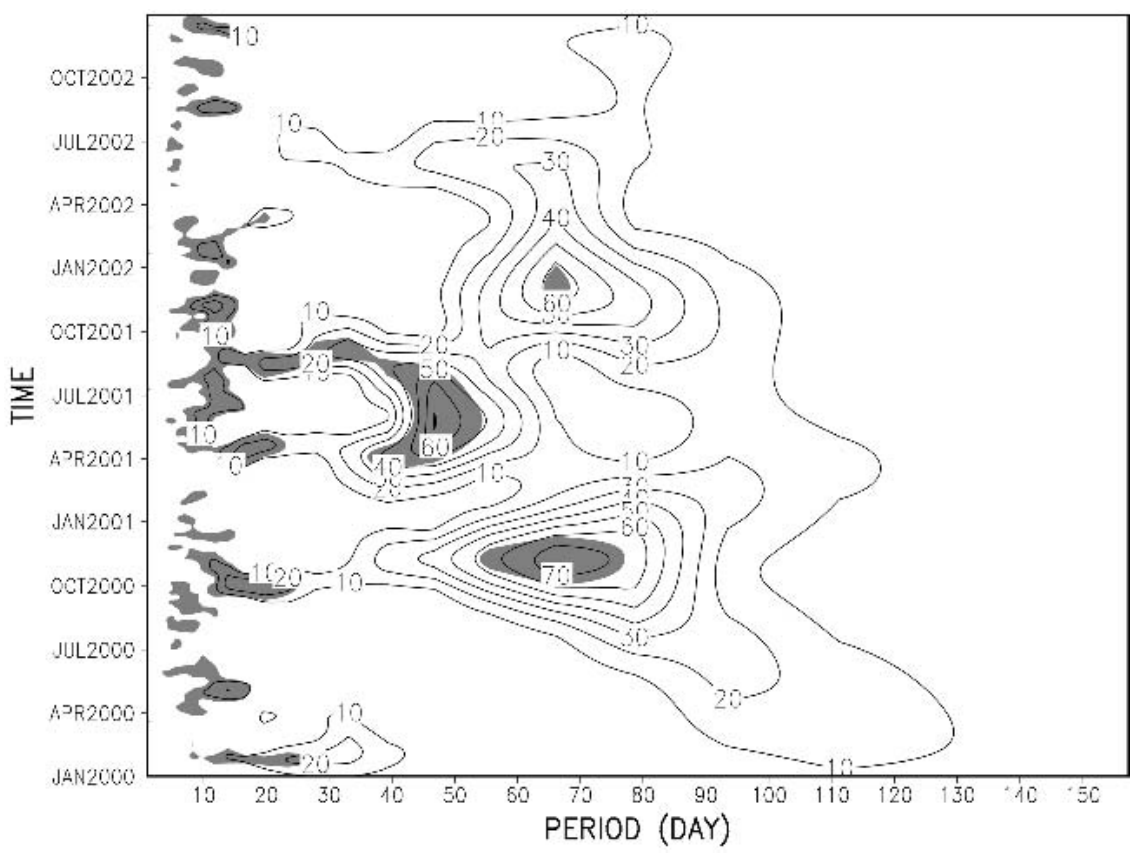

FIG. 3. Local wavelet power spectrum $\left(10^{-4} \mathrm{~mm}^{2}\right)$ using the Morlet wavelet for SSM/I CLW averaged over the stratus region of $10-25^{\circ} \mathrm{S}, 80-100^{\circ} \mathrm{W}$ (dashed box in Fig. 1a). Shade indicates regions with greater than $95 \%$ confidence for a red noise process with a lag-1 correlation coefficient of 0.88 . 


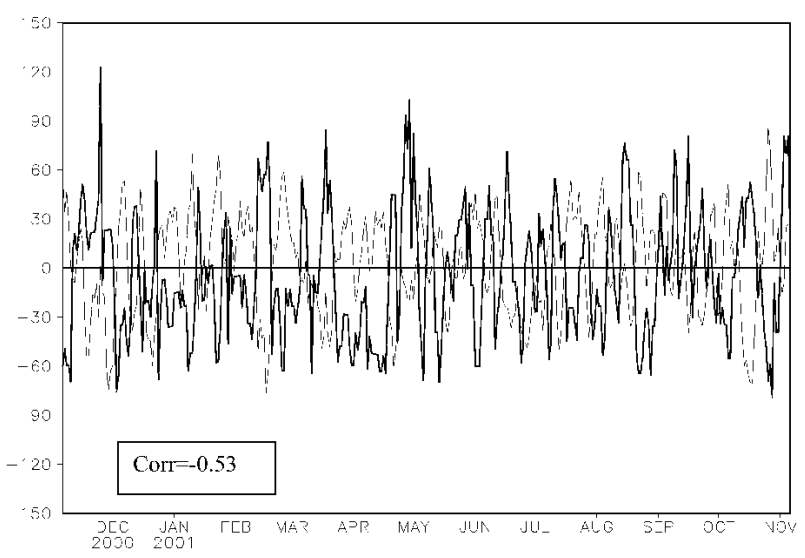

FIG. 4. SSM/I cloud liquid water at $20.125^{\circ} \mathrm{S}, 85.125^{\circ} \mathrm{W}$ (thick in $10^{-3} \mathrm{~mm}$ ) and incoming shortwave radiation (thin in $\mathrm{W} \mathrm{m}^{-2}$ ) measured by a buoy at $20.15^{\circ} \mathrm{S}, 85.15^{\circ} \mathrm{W}$ for a 1 -yr period of $7 \mathrm{Nov}$ 2000-6 Nov 2001, with their correlation coefficient on the left bottom corner. Seasonal variations have been removed with the harmonic analysis.

cold advection. We calculated surface temperature advection by using buoy-measured wind vectors and TMI SST gradient averaged in $17.5-22.5^{\circ} \mathrm{S}, 82.5-87.5^{\circ} \mathrm{W}$. It is found that the CLW is highly negatively correlated with the surface temperature advection. Surface air temperature is also highly negatively correlated with CLW, consistent with the highly positive correlation of the CLW with surface temperature advection. With surface air temperature decreasing due to the cold advection and the increased surface wind, both sensible and latent heat fluxes are increased and thus positively correlated with CLW variations.

Surface specific humidity is negatively correlated with CLW, an indication of dry advection in addition to the cold advection, but the correlation is only marginally significant. While previous radiosonde observations indicate significant correlations between cloud amount and relative humidity in the cloud layer (Al-

TABLE 1. Correlation coefficients of selected variables observed by the IMET buoy with SSM/I column cloud liquid water at $20.125^{\circ} \mathrm{S}, 85.125^{\circ} \mathrm{W}$. Correlations that are significant at the $99 \%$ level are boldfaced. Note that seasonal variations are removed before the correlations are calculated.

\begin{tabular}{lc}
\hline \hline \multicolumn{1}{c}{ Variable } & Correlation coefficient \\
\hline Sea surface temperature & -0.17 \\
Surface wind speed & $\mathbf{+ 0 . 3 2}$ \\
Surface zonal wind & $\mathbf{- 0 . 3 0}$ \\
Surface meridional wind & +0.16 \\
Sea level pressure & +0.12 \\
Air temperature & $\mathbf{- 0 . 2 7}$ \\
Surface temperature advection & $\mathbf{- 0 . 2 7}$ \\
Surface relative humidity & $\mathbf{- 0 . 0 2}$ \\
Specific humidity & $\mathbf{- 0 . 1 5}$ \\
Sensible heat flux & $\mathbf{+ 0 . 3 2}$ \\
Latent heat flux & $\mathbf{+ 0 . 3 2}$ \\
Surface incoming shortwave radiation & $\mathbf{- 0 . 4 9}$ \\
\hline
\end{tabular}

brecht 1981; Bretherton et al. 1995; Klein 1997), surface relative humidity is not correlated with cloud fluctuations at the IMET buoy. Surface humidity signal is weak or nonexistent possibly because of the competition between the moistening due to increased surface flux and drying due to the horizontal advection and enhanced vertical mixing.

\section{b. Large-scale structures from satellite measurements}

To examine the linkage between the large-scale circulation and the stratus cloud fluctuations, we composite surface wind velocity, column water vapor, SLP, and $500-\mathrm{hPa}$ geopotential height fields based on the time series of area-averaged SSM/I CLW over the subtropical southeast Pacific (Fig. 2). Days with this CLW index exceeding 1.5 standard deviations $(0.021 \mathrm{~mm})$ are classified as being in the positive phase of the CLW variability; those below -1.5 standard deviations as being in the negative phase. The 1.5 standard deviations are shown with dashed horizontal lines in Fig. 2. There are 78 and 70 days in the 3 -yr data record that are classified as the positive and negative phases of CLW variability, respectively. Data are averaged separately for these positive and negative phase days. We discuss the difference fields between the positive and negative phase composites. To determine the statistical significance of the difference field, we compute the degree of freedom as $\left(n_{x}+n_{y}-2\right)$ divided by the maximum of $\tau_{x}$ and $\tau_{y}$ at each grid point and use a two-sided Student $t$ test, where $n_{x}=78, n_{y}=70 ; \tau_{x}$ and $\tau_{y}$ are calculated with the method described in section $2 \mathrm{c}$.

Figure 5 presents the composite difference fields of CLW, column water vapor, surface temperature advection, and scalar wind speed based on SSM/I observations, and QuikSCAT wind vectors. Here the surface temperature advection is calculated by using QuikSCAT wind vectors and the TMI SST field instead of surface air temperature. This is a reasonable approximation given that surface air temperature does not differ much from the underlying SST. Increased CLW over the southeast Pacific is associated with an anomalous anticyclonic circulation centered to the south around $40^{\circ} \mathrm{S}, 85^{\circ} \mathrm{W}$ (Fig. 5a). The significant displacement of the anticyclone center south of the maximum CLW anomaly explains why the CLW-SLP correlation is only marginally positive at the IMET buoy (Table 1). The southeast trades are enhanced, and wind speed increases in the northern half of this anomalous anticyclonic circulation (Fig. 5b). Buoy observations confirm this positive CLW-wind speed correlation. At the IMET buoy site, wind velocity anomalies are dominated by the zonal component, consistent with CLW's high negative correlation with zonal wind and marginal positive correlation with meridional wind (Table 1).

Over the positive CLW anomalies in the subtropical South Pacific, anomalous winds are nearly perpendicular to the mean SST contours, resulting in a strong cold 

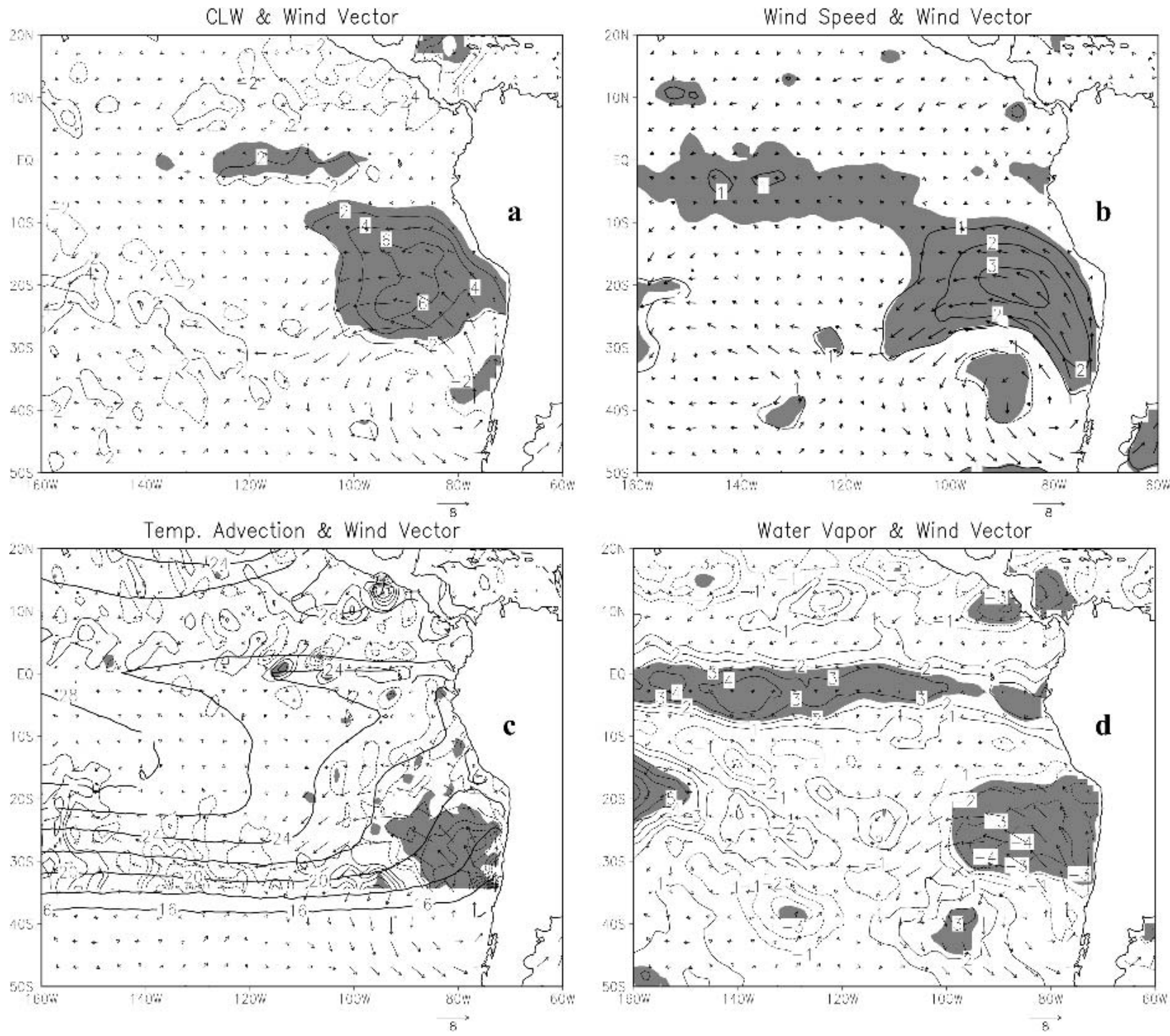

FIG. 5. Composite anomalies of (a) SSM/I CLW (contours in $10^{-2} \mathrm{~mm}$ ), (b) SSM/I wind speed (contours in $\mathrm{m} \mathrm{s}^{-1}$ ), (c) temperature advection (light contours in $0.3^{\circ} \mathrm{C}$ day $^{-1}$ ), and (d) SSM/I column water vapor (contours in $\mathrm{mm}$ ) between the positive and negative phases of CLW variability. Composite anomalies of QuikSCAT wind vector are also shown. Shade denotes regions where the differences pass the two-sided $t$ test at the $99 \%$ significance level. Three-year (2000-02) mean TMI SST (heavy contours in ${ }^{\circ} \mathrm{C}$ ) is also plotted in (c).

advection (Fig. 5c) that is consistent with the highly negative correlation with surface air temperature advection at the buoy. Negative anomalies of SSM/I column water vapor are observed to roughly coincide with those of CLW, another result of dry and cold advection from a cold ocean surface by anomalous winds. The cold and dry advection, together with increased wind speed, destabilizes the surface layer over the ocean and enhances surface latent and sensible heat fluxes, as observed by the IMET buoy. On the other hand, the increased boundary-layer offshore easterlies associated with the anomalous subtropical anticyclone support low-level divergence and thus subsidence in the stratus region. As a result, the subsidence warming, together with the cooling of the boundary layer due to cold advection, acts to enhance the capping temperature inversion, favorable for low-cloud formation (Klein and Hartmann 1993; Norris 1998). The enhanced subsidence and temperature inversion are indeed found in both ECMWF and NCEP-NCAR reanalyses (Fig. 6). The difference between the positive and negative phase composites is similar between two datasets but is greater in magnitude and deeper in height in the ECMWF reanalysis. At the positive phase of subseasonal CLW variability, the cold advection by surface flow cools the PBL, while the enhanced subsidence causes a warming above the inversion. The combined effect of surface cooling and free tropospheric warming 

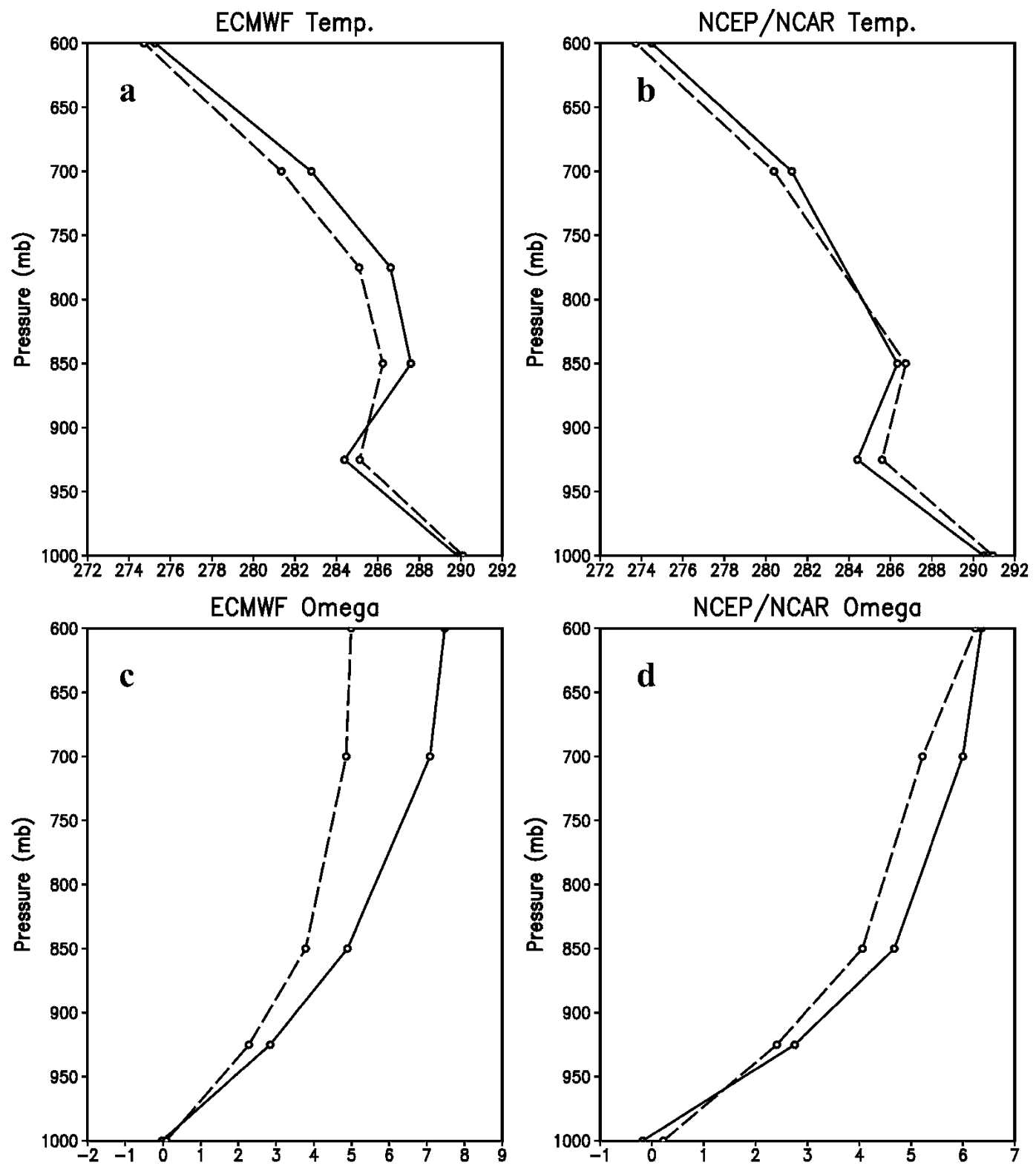

FIG. 6. Vertical profiles of (a), (b) temperature (K) and (c), (d) vertical velocity $\left(0.01 \mathrm{~Pa} \mathrm{~s}^{-1}\right)$ at $20^{\circ} \mathrm{S}, 85^{\circ} \mathrm{W}$ at the positive (solid) and negative (dashed) phases of subseasonal CLW variability, based on 2-yr (2000-01) daily mean ECMWF in (a) and (c) and NCEP-NCAR reanalyses in (b) and (d).

is to strengthen the temperature inversion, conducive to stratus formation.

Relatively large anomalies of column water vapor are found along the equator and in the SPCZ (Fig. 5d). The cause of these remote anomalies is beyond the scope of this study but may be indicative of interaction of the large-scale atmosphere circulation and stratus cloud deck. Based on a regional climate model, Wang et al. (2005) recently found that the stratus cloud deck over the southeast Pacific has a significant effect on the large-scale atmospheric circulation and the ITCZ through cloud-radiation-circulation feedback.

\section{c. Lead/lag relationships}

We now examine the lead/lag relations to infer causality. CLW peaks are selected with the following criteria: (i) the CLW anomaly exceeds a threshold of 0.015 $(-0.015) \mathrm{mm}$; (ii) it is the maximum (minimum) during the adjacent 6 days (total 7 days including the peak day); and (iii) CLW decreases (increases) in those adjacent days on both sides. The time for this peak is designated as "day 0". There are 30 such peaks for both positive and negative phase composites. Composites of various fields are constructed each day from 3 days 
prior to the peak to 3 days after the peak. The positive-negative composite difference is discussed below.

Figure 7 presents the composite differences of CLW, total and zonal wind speeds, SSTs, water vapor, and temperature advection at various lead/lag times. The temperature advection is calculated by using QuikSCAT wind vectors and the TMI SST field instead of surface air temperature. Note that all anomaly fields in Fig. 7 are spatially averaged over the southeast Pacific stratus region (the dashed box in Fig. 1a). Surface wind speed and temperature advection lead CLW by 1-2 days while SST lags CLW by 1-2 days. This indicates that on subseasonal time scales CLW variations over the southeast Pacific are strongly influenced by atmospheric circulation rather than by underlying SST changes. Our result of the temperature advection leading CLW by 1-2 days is different from Klein (1997), who found the best correlation of the low-cloud amount with temperature advection at zero lag. The phase difference is due in part to the fact that here we focused on the subseasonal variability of low clouds with time scales longer than 2 weeks, while Klein (1997) studied the synoptic variability of low clouds with a time period of several days (less than 5-6 days). Thus the phase shift between the surface advection and cloud amount in his work is not well resolved by using daily data. The SST lag, however, is consistent with the results of Klein (1997), who found that the low-cloud amount over the northeast Pacific is best correlated with SST lagging 1-2 days. Simultaneous negative SST correlation, though only marginally significant, is observed also by the

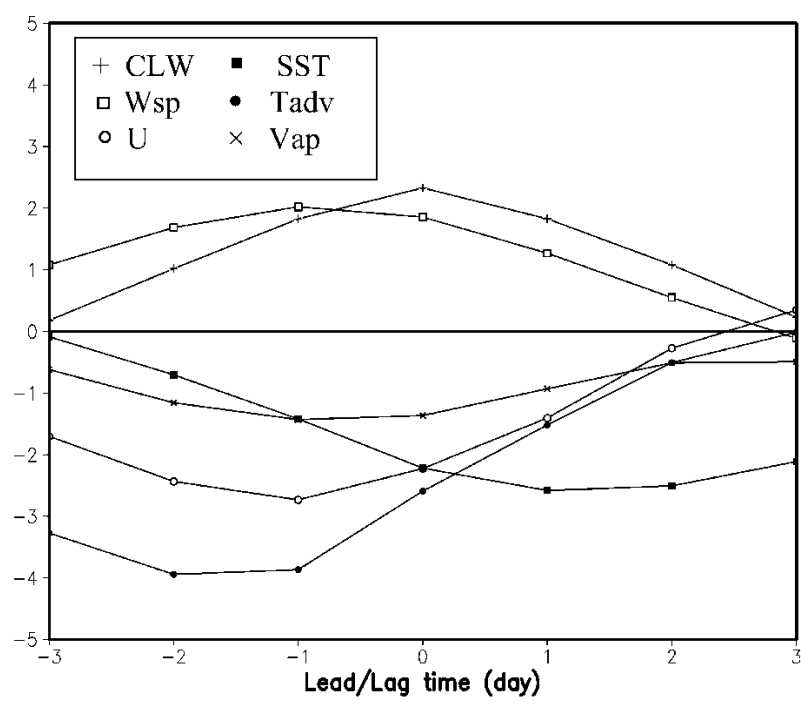

FIG. 7. Composite anomalies of CLW $(0.02 \mathrm{~mm})$, wind speed (Wsp in $\mathrm{m} \mathrm{s}^{-1}$ ), zonal wind ( $\mathrm{U}$ in $\mathrm{m} \mathrm{s}^{-1}$ ), TMI SST $(0.1 \mathrm{~K})$, water vapor (Vap in $\mathrm{mm}$ ), and temperature advection (Tadv in $0.1 \mathrm{~K}$ day $^{-1}$ ) as a function of the lead/lag time relative to the CLW maximum. All anomalies are spatially averaged over the subtropical southeast Pacific $\left(10^{\circ}-25^{\circ} \mathrm{S}, 80^{\circ}-100^{\circ} \mathrm{W}\right)$. See text for the composite method.
IMET buoy (Table 1). The SST decrease is likely due to enhanced entrainment across the bottom of the ocean mixed layer and increased surface turbulent heat flux in response to increased wind speed, reduced air temperature and humidity, and reduced incoming solar radiation. Note that Fig. 7 shows the composite differences between the positive and negative phases. For the positive (negative) phase only, the SSTs decrease (increase) about $0.1 \mathrm{~K}$ in 4 days, which would require an anomalous heat flux of about $50 \mathrm{~W} \mathrm{~m}^{-2}$ for a $50-\mathrm{m}$ deep ocean mixed layer. Based on our estimation, an increase by $0.02 \mathrm{~mm}$ in CLW would reduce shortwave radiation by about $20-30 \mathrm{~W} \mathrm{~m}^{-2}$, while an increase by $1-2 \mathrm{~m} \mathrm{~s}^{-1}$ in wind speed would induce an anomalous sensible and latent heat flux of about $10-20 \mathrm{~W} \mathrm{~m}^{-2}$.

\section{Discussion: Atmospheric circulation}

This section discusses the atmospheric circulation changes that lead to the variations in the South Pacific subtropical high, which cause subseasonal variations in the stratus cloud deck as discussed in the preceding section. Figure 8 portrays the differences of SLP and 500-hPa geopotential height between the positive and negative CLW phases, obtained using the same method as in section $3 b$ and the NCEP-NCAR reanalysis. An increase in CLW over the subtropical southeast Pacific is associated with a positive SLP anomaly center off the west coast of Chile, about $20^{\circ}$ south of the stratus region. This anomalous high pressure is consistent with the independent QuikSCAT observations of surface wind velocity (Fig. 5). At $500 \mathrm{hPa}$, geopotential height anomalies are roughly collocated with the SLP anomalies, indicating that this anomalous high off Chile has a barotropic structure in the vertical. The increase in CLW over the subtropical southeast Pacific is also associated with a weak negative SLP anomaly center off the southeast coast of Argentina and a positive SLP anomaly center in the midlatitudes of the South Atlantic. This anomaly wave train is more clearly reflected in the 500-hPa geopotential height field (Fig. 8b), indicating that there are possible connections among atmospheric circulations over the southeast Pacific and South Atlantic.

Figure 9 presents the composite anomalies of SLP and $500-\mathrm{hPa}$ geopotential height at various lead/lag times ( $-3 \sim 0$ day), obtained using the same method as in section 3c. Three days before CLW reaches its peak, a strong negative SLP (500-hPa geopential height) anomaly center occurs around $55^{\circ} \mathrm{S}, 110^{\circ} \mathrm{W}$ with a maximum value of $12 \mathrm{hPa}(120 \mathrm{gpm})$ while a strong positive SLP (500-hPa geopotential height) anomaly center appears around the southern tip of the South American continent. Both negative and positive anomaly centers then propagate eastward with a nearly constant distance of about $3000 \mathrm{~km}$ between them ( wavenumber 3 and 4). The negative anomaly center 

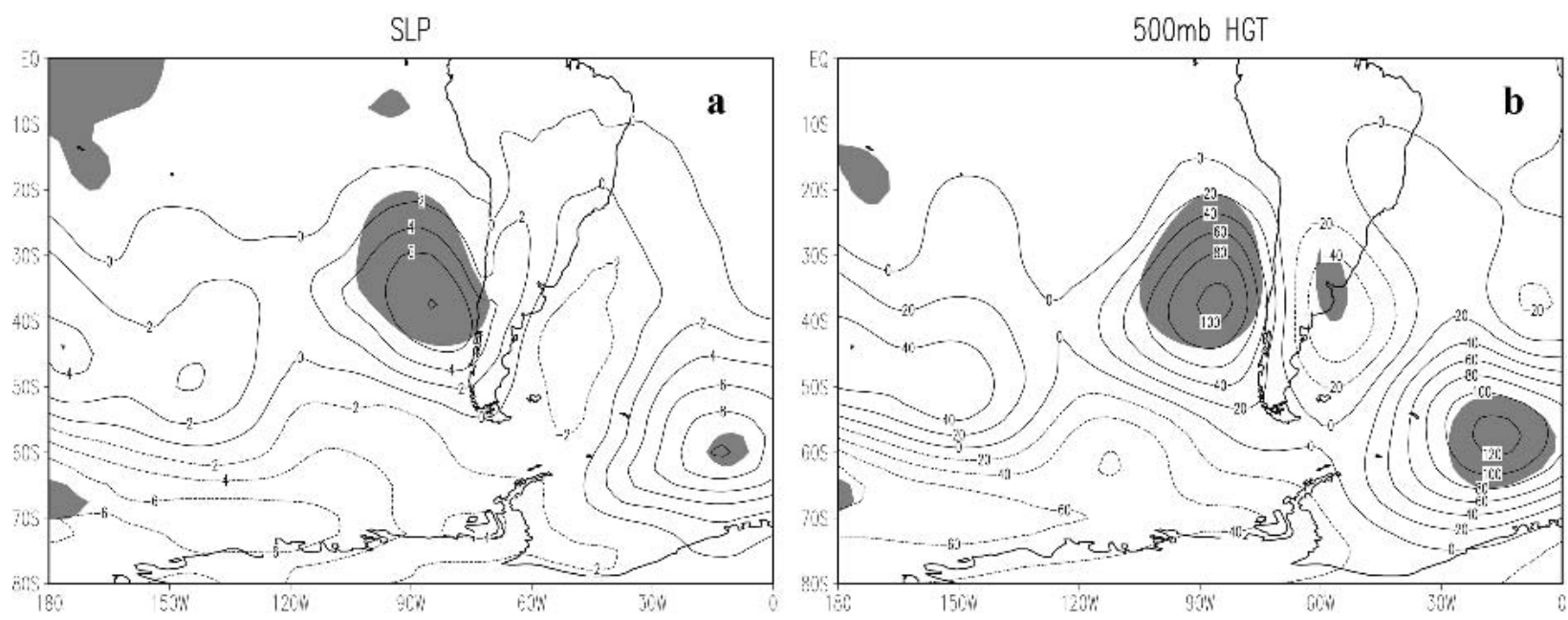

FIG. 8. Composite anomalies of (a) SLP (contours in hPa) and (b) 500-hPa geopotential height (contours in gpm) based on the NCEP-NCAR reanalysis. Shade denotes regions where the differences pass the two-sided Student's $t$ test at the $99 \%$ significance level.

eventually decays as it approaches the coast of South America, while the positive anomaly center keeps propagating eastward and reaches as far as the central South Atlantic. When these midlatitude anomalies travel eastward, a positive SLP (500-hPa geopotential height) anomaly center develops over the subtropical southeast Pacific just west of Chile. This subtropical anomaly center intensifies and reaches the maximum intensity 1 day before CLW reaches its peak. With these midlatitude anomalies propagating eastward, a negative anomaly center also develops over the southern part of South America and reaches its maximum intensity just 1 day after the subtropical positive anomaly over the southeast Pacific reaches its peak, indicating some delayed effects of the upstream positive anomalies over the southeast Pacific on the downstream negative anomalies over the southern portion of South America. The intensification of the negative anomalies may be associated with leeside cyclogenesis as the upper-level westerly flow crosses the narrow and steep Andes. This lagged relationship between the atmospheric circulation over the southeast Pacific and that over South America is also found by Wang and $\mathrm{Fu}$ (2004), who showed that the low-level jet (LLJ) intensity over on the eastern flank of the Andes is highly correlated with upstream zonal winds a few days earlier over the subtropical South Pacific. These associations among the midlatitude low, subtropical high over the southeast Pacific and the subtropical low over southern South America are confirmed in a one-point lead/lag correlation analysis of the 500-hPa geopotential height field with the base grid point at $30^{\circ} \mathrm{S}, 85^{\circ} \mathrm{W}$ (not shown). In addition, the advection by the midlatitude low of low potential vorticity air from low latitudes off South America may contribute to the development of the Pacific subtropical high.

The intensification of the Pacific subtropical high may also be associated with the blocking effect of the Andes Mountains. Garreaud et al. (2002) found that a coastal low off the west coast of Chile often develops as an upper-troposphere, midlatitude ridge over the $\mathrm{Pa}$ cific approaches the Andes. These coastal lows/ridges are also often observed along the west coast of North America (Nuss et al. 2000), and a common feature of these coastally trapped disturbances off North and South America is their poleward propagation. Based on numerical simulations, Garreaud and Rutllant (2003) showed that the coastal trough is largely due to the upwind barrier effect as the synoptic-scale low-level easterly flow impinges on the Andes. Here we propose a similar mechanism for the development of SLP anomalies off subtropical South America. As a midlatitude low pressure center travels eastward and approaches the west coast of South America, the onshore westerly winds intensify on the northern side of the low. Due to the blocking effect of the high Andes, air piles up near the coast, leading to an increase in SLP. Further studies are necessary to test this mechanism.

Finally, we discuss the mechanism for eastwardpropagating anomalies in the midlatitudes that cause the intensification of the subtropical high over the southeast Pacific. Over the last two decades many investigators have examined subseasonal variability of the Southern Hemisphere circulation in the middle and high latitudes. Kidson (1991) applied a 10-50-day bandpass filter to daily ECMWF analyses for 1980-88 and found that variations on this time scale contribute more than $40 \%$ of the daily variance in $500-\mathrm{hPa}$ geopotential over much of the middle and high latitudes of the Southern Hemisphere. EOF analysis of the unnormalized variance for all seasons shows that $49 \%$ of this variance can be explained by zonal wave trains centered on the South Pacific and southern Atlantic/Indian Oceans, a high-latitude mode of global extent, and a 

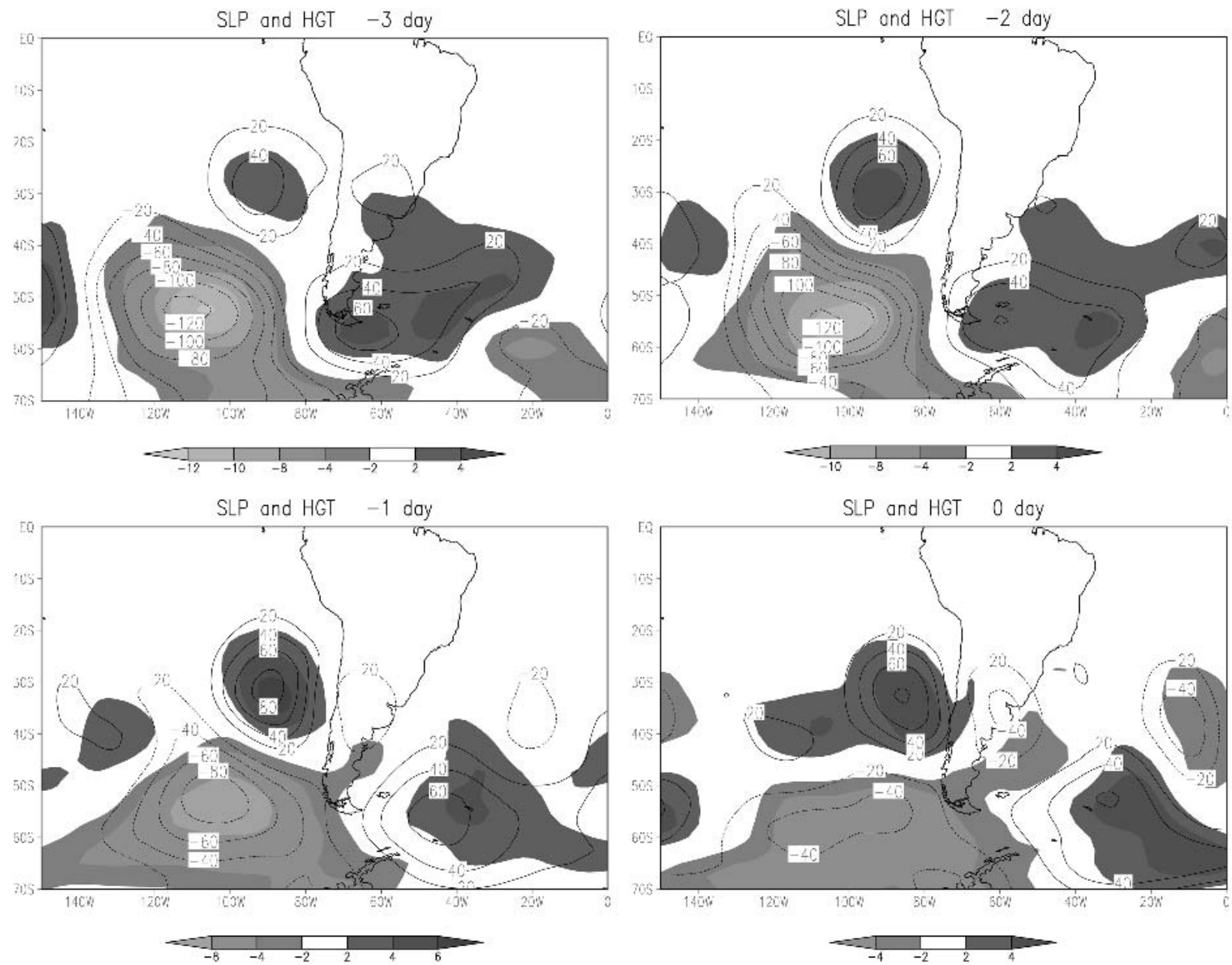

FIG. 9. Horizontal distributions of composite anomalies of NCEP-NCAR SLP (shaded in hPa) and 500-hPa geopotential height (contours in gpm) at various lead/lag times $(-3 \sim 0$ day) relative to the CLW maximum.

wavenumber-3 pattern at midlatitudes. All of the leading modes propagate eastward, but the most consistent movement is shown by the South Pacific wave train. This wavenumber- 4 pattern moves eastward at $4^{\circ}-7^{\circ}$ longitudes per day near $55^{\circ} \mathrm{S}$. Berbery et al. (1992) and Ambrizzi et al. (1995) also found that eastwardpropagating waves of zonal wavenumbers 3 and 4 are confined to a zonal belt between $40^{\circ}$ and $60^{\circ} \mathrm{S}$, with the polar jet acting as a waveguide. These eastwardpropagating wave trains have equivalent barotropic structure in the vertical and their phase tilts slightly westward with height (Ghil and Mo 1991; Kidson 1991; Lau et al. 1994), consistent with the vertical structures of the eastward-propagating anomalies presented here. Kiladis and Weickmann (1997) further suggested that these eastward-propagating wave trains are forced by convection in the Indian and Australasian sectors.

\section{Summary}

New satellite and buoy observations are used to investigate subseasonal variability in the Sc cloud deck over the subtropical southeast Pacific. SSM/I CLW is highly correlated with the incoming shortwave radiation at the sea surface measured by an IMET buoy off South America, demonstrating that the satellitemeasured CLW can be used to study cloud variability. On subseasonal time scales, SSM/I CLW is significantly correlated with local wind velocity, surface air temperature, and sensible and latent heat fluxes based on the buoy observations. This result is consistent with that of Klein et al. (1995) and Klein (1997) for synoptic variability in the northeast Pacific stratus deck based on weather station observations.

A lead/lag composite analysis show that surface wind speed and its temperature advection lead CLW by 1-2 days while local SST lags CLW by 1-2 days, indicating that on subseasonal time scales, CLW is strongly influenced by atmospheric circulation changes rather than by the underlying ocean. An increase in CLW is associated with an anomalous positive SLP center and an anomalous anticyclonic circulation (enhanced subtropical high) over the southeast Pacific west of South 
America, with enhanced surface southeasterly winds in the stratus cloud deck region. These anomalous winds blow in the direction of the mean SST gradient, advecting cold and dry air into the stratus region from the coastal region off Chile where SST is kept cold by the strong upwelling. The cold and dry advection together with increased wind speed helps destabilize the surface layer over the ocean, increasing surface latent and sensible heat fluxes. On the other hand, the enhanced offshore easterlies associated with the anomalous anticyclone cause low-level divergence and subsidence in the southeast Pacific stratus region. Together, the subsidence warming and the cooling of the PBL act to enhance the capping temperature inversion, favoring lowcloud formation.

The lead/lag composite analysis indicates that an increase in CLW and a strengthening of the subtropical high over the southeast Pacific are associated with an eastward-propagating low-pressure disturbance in the midlatitudes, suggesting possible interactions between the subtropics and midlatitudes. In addition, the high Andes Mountains along the west coast of South America may act to amplify the subtropical high by blocking the eastward-propagating midlatitude disturbance.

While the southeast Pacific stratus deck plays an important role in basin-scale climate (Philander et al. 1996; Ma et al. 1996; Xie 2004a), its realistic simulation is still a challenge in many global and regional climate models. Recognizing the need to better describe and understand this important element of Pacific climate, the stratus cloud deck off the west coast of South America is a focus of the recent EPIC field campaign (Bretherton et al. 2004). A follow-on campaign, the Variability of the American Monsoon Systems (VAMOS) Program's Ocean-Cloud-AtmosphereLand Study (VOCALS), is under planning for a detailed investigation of this subtropical stratus cloud deck. This cloud deck involves complex interactions among atmospheric circulation, mixing, radiation, microphysics, and ocean. Our observational study of its subseasonal variability provides a benchmark for model simulation. A realistic model should correctly simulate this subseasonal cloud variability and its relationship with atmospheric circulation. Recently, we have used a regional atmospheric model to simulate the southeast Pacific cloud deck (Wang et al. 2004) and study the effect of the Andes (Xu et al. 2004). The simulation of subseasonal variability of this cloud deck and investigation of its vertical structure and mechanism using this model are a subject of our future study.

Acknowledgments. We wish to thank Chris Bretherton for constructive comments, and Jan Hafner for data archiving. We are also grateful to three anonymous reviewers for their comments, which helped improve the manuscript. SSM/I, TMI, and QuikSCAT data are processed by Remote Sensing Systems and buoy data are made available by R. Weller at WHOI from the surface mooring, which has been funded through the Cooperative Institute for Climate and Ocean Research (CICOR) by the NOAA Office of Global Programs Pan American Climate Study and Climate Observation Programs. This work was supported by NOAA PACS Program (NA17RJ230), NSF (ATM01-04468), NASA (NAG5-10045), and by the Japan Agency for MarineEarth Science and Technology (JAMSTEC) through its sponsorship of the International Pacific Research Center. C. Torrence and G. Compo authored the wavelet software (and made it available online at http:// paos.colorado.edu/research/wavelets). H. Xu preformed this work at IPRC while on leave from the Department of Atmospheric Sciences, Nanjing Institute of Meteorology.

\section{REFERENCES}

Albrecht, B. A., 1981: Parameterization of trade-cumulus cloud amount. J. Atmos. Sci., 38, 97-105.

_ D. A. Randall, and S. Nicholls, 1988: Observations of marine stratocumulus during FIRE. Bull. Amer. Meteor. Soc., 69, 618-626.

Ambrizzi, T., B. J. Hoskins, and H.-H. Hsu, 1995: Rossby wave propagation and teleconnection patterns in the austral winter. J. Atmos. Sci., 52, 3661-3672.

Berbery, E. H., J. Nogues-Paegle, and J. D. Horel, 1992: Wavelike Southern Hemisphere extratropical teleconnections. J. Atmos. Sci., 49, 155-177.

Betts, A. K., 1990: The diurnal variation of California coastal stratocumulus from two days of boundary layer soundings. Tellus, 42A, 302-304.

Bretherton, C. S., E. Klinker, A. K. Betts, and J. Coakley, 1995: Comparison of ceilometer, satellite, and synoptic measurements of boundary layer cloudiness and the ECMWF diagnostic cloud parameterization scheme during ASTEX. $J$. Atmos. Sci., 52, 2736-2751.

_ and Coauthors, 2004: The EPIC 2001 stratocumulus study. Bull. Amer. Meteor. Soc., 85, 967-977.

Del Genio, A. D., M.-S. Yao, W. Kovari, and K. K. W. Lo, 1996: A prognostic cloud water parameterization for global climate models. J. Climate, 9, 270-304.

Garreaud, R. D., and J. Rutllant, 2003: Coastal lows along the subtropical west coast of South America: Numerical simulation of a typical case. Mon. Wea. Rev., 131, 891-908.

,-- , and H. Fuenzalida, 2002: Coastal lows along the subtropical west coast of South America: Mean structure and evolution. Mon. Wea. Rev., 130, 75-88.

Ghil, M., and K. Mo, 1991: Instraseasonal oscillations in the global atmosphere. Part II: Southern Hemisphere. J. Atmos. Sci., 48, 780-790.

Gordon, C. T., A. Rosati, and R. Gudgel, 2000: Tropical sensitivity of a coupled model to specified ISCCP low clouds. $J$. Climate, 13, 2239-2260.

Hashizume, H., S.-P. Xie, M. Fujiwara, M. Shiotani, T. Watanabe, Y. Tanimoto, W. T. Liu, and K. Takeuchi, 2002: Direct observations of atmospheric boundary layer response to SST variations associated with tropical instability waves over the eastern equatorial Pacific. J. Climate, 15, 3379-3393.

Hosom, D. S., R. A. Weller, R. E. Payne, and K. E. Prada, 1995: The IMET (improved meteorology) ship and buoy systems. $J$. Atmos. Oceanic Technol., 12, 527-540.

Kalnay, E., and Coauthors, 1996: The NCEP/NCAR 40-Year Reanalysis Project. Bull. Amer. Meteor. Soc., 77, 437-471.

Kidson, J. W., 1991: Intraseasonal variations in the Southern Hemisphere circulation. J. Climate, 4, 939-953.

Kiladis, G. N., and K. M. Weickmann, 1997: Horizontal structure 
and seasonality of large-scale circulations associated with submonthly tropical convection. Mon. Wea. Rev., 125, 19972013.

Klein, S. A., 1997: Synoptic variability of low-cloud properties and meteorological parameters in the subtropical trade wind boundary layer. J. Climate, 10, 2018-2039.

_ , and D. L. Hartmann, 1993: The seasonal cycle of low stratiform clouds. J. Climate, 6, 1587-1606.

,-- , and J. R. Norris, 1995: On the relationships among low cloud structure, sea surface temperature, and atmospheric circulation in the summertime northeast Pacific. J. Climate, 8, 1140-1155.

Lau, K.-M., P.-J. Sheu, and I.-S. Kang, 1994: Multiscale lowfrequency circulation modes in the global atmosphere. J. Atmos. Sci., 51, 1169-1193.

Leith, C. E., 1973: The standard error of time-average estimates of climatic means. J. Appl. Meteor., 12, 1066-1069.

Ma, C.-C., C. R. Mechoso, A. W. Robertson, and A. Arakawa, 1996: Peruvian stratus clouds and the tropical Pacific circulation: A coupled ocean-atmosphere GCM study. J. Climate, 9, 1635-1645.

Minnis, P., P. W. Heck, D. F. Young, C. W. Fairall, and J. B. Snider, 1992: Stratocumulus cloud properties derived from simultaneous satellite and island-based instrumentation during FIRE. J. Appl. Meteor., 31, 317-339.

Nicholls, S., 1984: The dynamics of stratocumulus: Aircraft observations and comparisons with a mixed layer model. Quart. J. Roy. Meteor. Soc., 110, 783-820.

Norris, J. R., 1998: Low cloud structure over the ocean from surface observations. Part II: Geographical and seasonal variations. J. Climate, 11, 383-403.

_ cloudiness and sea surface temperature. J. Climate, 7, 19151925.

Nuss, W. A., and Coauthors, 2000: Coastally trapped wind reversals: Progress toward understanding. Bull. Amer. Meteor. Soc., 81, 719-743.

Philander, S. G. H., D. Gu, D. Halpern, G. Lambert, N.-C. Lau, T. Li, and R. C. Pacanowski, 1996: Why the ITCZ is mostly north of the equator. J. Climate, 9, 2958-2972.

Randall, D. A., J. A. Coakley Jr., C. W. Fairall, R. A. Kropfli, and D. H. Lenschow, 1984: Outlook for research on subtropical marine stratiform clouds. Bull. Amer. Meteor. Soc., 65, 12901301.

Rozendaal, M. A., and W. B. Rossow, 2003: Characterizing some of the influences of the general circulation on subtropical marine boundary clouds. J. Atmos. Sci., 60, 711-728.

, C. B. Leovy, and S. A. Klein, 1995: An observational study of diurnal variations of marine stratiform cloud. J. Climate, $\mathbf{8}$, $1795-1809$.

Wang, H., and R. Fu, 2004: Influence of cross-Andes flow on the South American low-level jet. J. Climate, 17, 1247-1262.

Wang, Y., S.-P. Xie, H. Xu, and B. Wang, 2004: Regional model simulations of boundary layer clouds over the southeast $\mathrm{Pa}$ cific off South America. Part I: Control experiment. Mon. Wea. Rev., 132, 274-296.

- _ B. Bang, and H. Xu, 2005: Large-scale atmospheric forcing by southeast Pacific boundary layer clouds: A regional model study. J. Climate, in press.

Weare, B., 1994: Interrelationships between cloud properties and SSTs on seasonal and interannual time scales. J. Climate, 7, 248-260.

Weller, R. A., and S. P. Anderson, 1996: Surface meteorology and air-sea fluxes in the western equatorial Pacific warm pool during the TOGA coupled ocean-atmosphere response experiment. J. Climate, 9, 1959-1992.

Wentz, F. J., 1997: A well calibrated ocean algorithm for SSM/I. J. Geophys. Res., 102, 8703-8718.

- C. Gentemann, D. Smith, and D. Chelton, 2000: Satellite measurements of sea surface temperature through clouds. Science, 288, 847-850.

Wood, R., C. S. Bretherton, and D. C. Hartmann, 2002: Diurna cycle of liquid water path over the subtropical and tropical oceans. Geophys. Res. Lett., 29, 2092, doi:10.1029/ 2002GL015371.

Wylie, D., B. B. Hinton, and K. Kloesel, 1989: The relationship of marine stratus clouds to wind and temperature advection. Mon. Wea. Rev., 117, 2620-2625.

Xie, S.-P., 2004a: The shape of continents, air-sea interaction, and the rising branch of the Hadley circulation. The Hadley Circulation: Past, Present and Future, H. F. Diaz and R. S. Bradley, Eds., Springer-Kluwer Academic, in press.

- 2004b: Satellite observations of cool ocean-atmosphere interaction. Bull. Amer. Meteor. Soc., 85, 195-208.

—, W. T. Liu, Q. Liu, and M. Nonaka, 2001: Far-reaching effects of the Hawaiian Islands on the Pacific oceanatmosphere system. Science, 292, 2057-2060.

$\mathrm{Xu}, \mathrm{H}$., Y. Wang, and S.-P. Xie, 2004: Effects of the Andes on eastern Pacific climate: A regional atmospheric model study. J. Climate, 17, 589-602. 